\title{
Regional differences in injury incidence in European professional football
}

\author{
Markus Waldén, Martin Hägglund, J Orchard, K Kristenson and Jan Ekstrand
}

\section{Linköping University Post Print}

\section{Tweet}

N.B.: When citing this work, cite the original article.

This is the pre-reviewed version of the following article:

Markus Waldén, Martin Hägglund, J Orchard, K Kristenson and Jan Ekstrand, Regional differences in injury incidence in European professional football, 2013, Scandinavian Journal of Medicine and Science in Sports, (23), 4, 424-430.

which has been published in final form at:

http://dx.doi.org/10.1111/j.1600-0838.2011.01409.x

Copyright: Wiley-Blackwell

http://eu.wiley.com/WileyCDA/Brand/id-35.html

Postprint available at: Linköping University Electronic Press

http://urn.kb.se/resolve?urn=urn:nbn:se:liu:diva-96421 


\section{REGIONAL DIFFERENCES IN INJURY INCIDENCE IN EUROPEAN}

\section{PROFESSIONAL FOOTBALL}

\section{Running head:}

Regional differences in professional football

M. Waldén, MD, PhD; ${ }^{1}$ M. Hägglund, PT, $\mathrm{PhD} ;{ }^{1}$ J. Orchard, MD, $\mathrm{PhD} ;{ }^{2}$ K. Kristenson, MS, PhD graduate; ${ }^{1} \mathrm{~J}$. Ekstrand, $\mathrm{MD}, \mathrm{PhD}^{1}$

${ }^{1}$ Department of Medical and Health Sciences, Linköping University, Sweden

${ }^{2}$ School of Public Health, University of Sydney, Australia

\section{Correspondence should be addressed to:}

Dr Markus Waldén

Department of Orthopaedics

Box 351

28125 Hässleholm, Sweden

Tel: +46 451296470

Fax: +46 451296478

E-mail: markus.walden@telia.com

\section{Key words:}

ACL, climate, epidemiology, Köppen, soccer, weather 


\section{ABSTRACT}

The objective of this study was to investigate regional differences in injury incidence in men's professional football in Europe. A nine-season prospective cohort study was carried out between 2001/02 and 2009/10 involving 1357 players in 25 teams from nine countries. Teams were categorized into different regions according to the Köppen-Geiger Climate Classification System. Teams from the northern parts of Europe $(n=20)$ had higher incidences of injury overall (rate ratio 1.12, 95\% CI 1.06 to 1.20 ), training injury (rate ratio 1.16 , 95\% CI 1.05 to 1.27 ), and severe injury (rate ratio $1.29,95 \%$ CI 1.10 to 1.52 ), all statistically significant, compared to teams from more southern parts $(\mathrm{n}=5)$. In contrast, the anterior cruciate ligament injury incidence was lower in the northern European teams with a statistically significant difference (rate ratio 0.43, 95\% CI 0.25 to 0.77), especially for non-contact anterior cruciate ligament injury (rate ratio 0.19 , 95\% CI 0.09 to 0.39). In conclusion, this study suggests that there are regional differences in injury incidence of European professional football. However, further studies are needed to identify the underlying causes. 


\section{INTRODUCTION}

Injury risk factors in sports have traditionally been divided into two main categories: intrinsic (individual) and extrinsic (environmental) factors (Bahr \& Holme, 2003; Murphy et al., 2003). Examples of intrinsic risk factors are sex, player age, previous injury, strength, flexibility and anatomical alignments, whereas extrinsic risk factors comprise playing level, weather condition, playing surface, footwear, use of brace or other equipment etc. Historically, most studies have focused on the influence of different intrinsic risk factors on the injury risk, many of them nonmodifiable (Bahr \& Holme, 2003; Alentorn-Geli, 2009). Weather condition is an example of an extrinsic risk factor that has been only scarcely investigated in the literature and the few existing studies come from American or Australian Rules football (Orchard et al., 1999; Orchard \& Powell, 2003). In football (soccer), it has previously been shown that female amateur teams from northern Sweden have a higher injury incidence during match play than teams from southern Sweden (Jacobson \& Tegner, 2006), and that the male first leagues in Denmark and Sweden differ regarding both training and severe injury incidence (Hägglund et al., 2005a). Moreover, preliminary findings from our study group indicated that clubs from the northern parts of Western Europe have a higher incidence of match injury and severe injury compared to clubs from more southern countries located near the Mediterranean Sea, but sub-group analyses of specific injuries was not possible due to the limited sample (Waldén et al., 2005).

The objective of this study was to investigate regional differences in injury incidence in men’s professional football in Europe. Our hypothesis was that the injury incidence is lower for teams coming from southern Europe based on our previous observations (Waldén et al., 2005). 


\section{METHODS}

A prospective cohort study has been carried out on men’s professional football in collaboration with the Union of European Football Associations (UEFA) since 2001. The injury characteristics for this cohort have previously been published for both the first season and the six subsequent ones (Waldén et al., 2005; Ekstrand et al., 2010). Additionally, the full methodology has been reported in detail previously (Hägglund et al., 2005b), and is only briefly summarized below.

\section{Participants}

A total of 26 top-level professional European football clubs were followed over a varying number of seasons from 2001/2002 to 2009/2010. All clubs play on natural grass at their home venues. All players belonging to the first team squads each season were invited to participate in the study. Players injured before exposure data was collected were included, but their present injuries were not taken into account. Players who were transferred to other clubs or finished their contracts due to other reasons before the end of a season were included for as long as they participated.

\section{Data collection}

A member of the medical or coaching staff registered individual exposure in minutes during all club and national team training sessions and matches. All time-loss injuries were recorded immediately after the event by a club medical officer. Injury cards and exposure records were sent to the study group monthly. All injuries were followed until return to football, except for careerending injuries, even if the player was transferred during the injury period.

\section{Definitions}

The operational definitions used in this study are summarized in Table 1. Injury was defined as any 
physical complaint sustained by a player that results from a football training or match and leads to the player being unable to participate in future football training or match play (Hägglund et al., 2005b; Fuller et al., 2006). A player was considered injured until the club medical officer allowed full participation in all types of training or match play (Hägglund et al., 2005b). Foul play was determined according to the decision of the referee for match injuries. Non-contact injury was defined as an injury resulting without player contact.

Insert Table 1 near here

\section{Classification of regions}

Because this study aimed for a more formal comparison between zones, the different regions in Europe were categorized according to climate type using the updated Köppen-Geiger Climate Classification System (Kottek et al., 2006). This system is divided in five different climate types (A-E) based on the average monthly temperature and precipitation. Each main category is further divided into several sub-types by adding two lower case letters: the first letter considers the precipitation and the second letter the air temperature. In Europe, the dominating climate types are Mediterranean (Csa and Csb) with warm/hot and dry summer together with wet winter, Humid Subtropical (Cfa) with hot humid summer and cool winter, Marine West Coast (Cfb) with warm summer, but no dry season, Humid Continental (Dfb) with warm summer and severe winter without any dry season, and Subarctic (Dfc) with cool summer and a severe and dry winter. Briefly, the Mediterranean climate type is found in Portugal, Spain, most of Italy, southern coastal Croatia, Greece and the southern parts of France while the Marine West Coast climate type is represented by the rest of France (except the Alps), Great Britain, Belgium, the Netherlands, Germany, the Czech Republic, Austria, Hungary, Denmark, southern Sweden and western Poland. 
The Humid Subtropical climate type covers less of Europe and is typically found in northern Italy, the coastal parts of Slovenia and northern Croatia as well as the Black Sea coast of Bulgaria, Romania, Russia and Ukraine. The Humid Continental climate dominates in Eastern Europe, thus including for example the rest of the southwestern parts of Russia, Romania and Ukraine, but also the eastern brim of Poland, Slovakia, Belarus, and the three Baltic countries. Finally, the Subarctic climate is found in northern Sweden, Finland, most of Norway, and the northwest parts of Russia.

\section{Ethics}

Written informed consent was collected from each player. The study design was approved by the UEFA Medical Committee and the UEFA Football Development Division.

\section{Statistical analyses}

The categorization of the teams into the different climate types was done by two of the authors (MW and MH) based on the Köppen-Geiger map (Kottek et al., 2006). One team (FC Shaktar Donetsk from Ukraine) has participated for three seasons since 2007/08, but was excluded from the present climate analyses since it was the only team representing the Dfb climate type (Table 2). The clubs were divided in two groups: one "Northern” group representing teams with Cfa and Cfb climate types ( $n=20,90$ team-seasons) and one "Southern” group representing teams with Csa and Csb climate types (n=5, 27 team-seasons). Exposure data were plotted in histograms and distributions of data were determined by visual inspection. Since the exposure data were approximately normally distributed, mean values are presented with corresponding standard deviation (SD) and the Student's t-test was used for between-group comparisons. Injury incidence is expressed as the number of injuries per 1000 exposure hours (Table 1), with corresponding 95\% confidence interval (95\% CI). Between-group differences in injury incidence were compared 
using a rate ratio (RR) significance tested with z-statistics (Lindenfeld et al., 1994). RR was calculated as the incidence in the northern group divided by the incidence in the southern group and the $\mathrm{CI}$ for the ratio was calculated according to the following formula: RR/exponent [1.96*standard error $\left.{ }_{\mathrm{RR}}\right]$ to $\mathrm{RR} *$ exponent $\left[1.96 *\right.$ standard error $_{\mathrm{RR}}$ ] where the standard error ${ }_{\mathrm{RR}}=\sqrt{ }$ [1/injuries $_{\text {(Northern group) }}+1$ /injuries (Southern group) $_{\text {) }}$. Between-group differences in injury incidence were calculated separately for training and match injuries for all analyses except for foul play (only match injuries) and overuse (only overall injuries). A difference in non-contact injury incidence was analysed only for ACL injuries, since this data have been collected as a part of a sub-study from the entire period (Waldén et al., 2011), but only as a matter of routine for all injuries since 2004/2005. All analyses were two-sided and the significance level was set at $P<0.05$.

Insert Table 2 near here 


\section{RESULTS}

In total, 117 team-seasons for 1357 players with 3138 partial or complete player-seasons were included in the study, the Northern group contributing with 1100 players and 2453 player-seasons.

\section{Exposure}

During the study period, 773563 exposure hours was recorded; 499238 training hours and 96260 match hours in the Northern group, and 149948 training hours and 28118 match hours in the Southern group, respectively. The mean training exposure per player was significantly lower in the Northern group compared to the Southern group (203.4 (74.5) vs. 218.9 (69.4) hours, $P<0.0001$ ), but there was no statistically significant difference in mean match exposure per player (39.2 (23.7) vs. 41.1 (26.9) hours, $P=0.08$ ). However, the mean number of team matches per season was lower in the Northern group with a statistically significant difference (32.3 (17.3) vs. 34.8 (18.5) matches, $P=0.001)$.

Insert Tables 3 and 4 near here

\section{Injury incidence}

In total, 5949 time-loss injuries were recorded. Teams in the Northern group had significantly higher incidences of injury overall and of both traumatic and overuse injury (Table 3). Taking injury severity into account, all injuries with lay-off of more than three days were more frequent in the Northern group, but more pronounced for severe injuries. Upper body, trunk and lower leg 
injuries, including common overuse injuries such as low back pain (LBP) and Achilles tendinopathy, were also more common among teams in the Northern group.

No statistically significant differences in injury incidence were seen overall, or separated by training or match play, for the four most common injury locations in the lower limbs (hip/groin, thigh, knee and ankle). Analysis of specific injury sub-types for these locations showed no statistically significant differences for thigh strains (both quadriceps and hamstrings) or knee and ankle sprains in general. However, the ACL injury incidence was lower in the Northern group with a statistically significant difference (Table 4); in particular, the incidence of non-contact ACL injury was considerably lower (0.02 [12 injuries] vs. 0.11 [19 injuries] non-contact ACL injuries per 1000 hours, RR 0.19, 95\% CI 0.09 to $0.39, P<0.001$ ). Finally, the contusion incidence (N=958) did not differ between groups (1.26 vs. 1.15 injuries per 1000 hours, RR 1.24, 95\% CI 1.03 to $1.50, P=0.23)$, whereas the incidence of match injury resulting from foul play $(\mathrm{N}=688)$ was significantly higher in the Northern group (5.79 vs. 4.66 injuries per 1000 hours, RR 1.24, 95\% CI 1.03 to $1.50, P=0.03)$.

The overall injury incidence varied during the season and there was a deviation of the curves for the groups primarily during the first half of the season between July and November (Figure 1). However, there was an even more marked deviation of the curves for non-contact ACL injury incidence during most of the season (Figure 2).

Insert Figures 1 and 2 near here 


\section{DISCUSSION}

The principal finding of the present study was that the injury incidence in general was higher in teams located in northern Europe compared to more southern teams. Interestingly, however, noncontact ACL injuries were more common in the southern teams.

\section{Regional differences in injury incidence}

The rationale for analysing the injury incidence for different geographical regions in Europe is that in the first-season report of this cohort, the four clubs from England and the Netherlands had higher incidences of match injury and severe injury than the seven clubs from France, Italy and Spain (Waldén et al., 2005). The overall result of the present study is basically in line with the trend found in that paper, but in the first-season report the teams were arbitrarily divided into northern and southern regions based on latitude of country without formally considering climate differences. We therefore decided to categorize the regions according to the Köppen-Geiger classification which is a well-established climate system that has undergone only minor changes over the years (Kottek et al., 2006). The biggest difference between the classification in this study compared to the first-season report is that the French and northern Italian teams were not included in the Southern group, since they belong to the Cfb and Cfa climate types, respectively.

Nevertheless, this study has shown an obvious “northern bias” with a higher general injury incidence among teams from regions in northern Europe with Marine West Coast or Humid Subtropical climate types compared to more southern teams with a Mediterranean climate type. It is likely that there are several factors contributing to the trend demonstrated. One possible explanation could be heavier training and match load in the Northern group, but there was only 
small between-group differences found in exposure variables and, although statistically significant, the practical relevance can be questioned. Another factor to consider might be regional differences in tactics, playing style and playing intensity. The speed of the game, the fighting spirit, and the number of duels has historically been very high, for example, in England and Scotland, but these factors have not been studied from an injury perspective. Similarly, injuries due to foul play were more frequent in the Northern group, and although a few studies have evaluated the referee standards of the game (Andersen et al., 2004; Fuller et al., 2004), the influence of any regional differences in referee decisions and interpretation of the rules is unclear.

The northern teams suffered from more overuse problems, and although different attitudes to sit players out or keep them playing despite pain might be present (Bahr, 2009), climate-related differences in ground hardness where harder pitches are expected to yield higher ground reaction forces and loading of the tissues also needs to be considered. It is, however, unlikely that climaterelated factors are the main cause of the higher injury incidences found in the Northern group, since the difference seems to be minimal during the actual winter period where the Mediterranean teams should suffer less from poor pitches and severe weather conditions. In contrast, the noncontact ACL injury incidence was considerably higher in the Southern group during almost all months of the season. Even though no specific weather condition variables such as temperature, rainfall, wind or evaporation were collected in the present study, the most plausible explanation to this "southern bias" is higher shoe-surface traction due to a warmer climate. In line with our findings, a northern bias (i.e. analogous to a southern bias in Europe) has been shown for noncontact ACL injuries in the Australian Football League (AFL) (Orchard et al., 1999). Interestingly, the southern AFL teams all come from a state (Victoria) that has the same climate type (Cfb) as most of the teams in our Northern group in Europe, whereas the northern AFL teams come from 
states with varying climate types (all warmer). It has, however, been suggested that it might be differences in grass types and not the variation in weather variables per se that is responsible for the increased ACL injury incidence among the northern AFL teams (Orchard et al., 2005). It would be expected that ryegrass (Lolium perenne) would be the predominant grass type for most grounds in Europe, but that this would be mixed with Poa pratensis in the colder regions and perhaps Cynadon dacytlon in the early-season in some Mediterranean regions. This study was, however, unable to take into account the actual grass types as well as practices at the various grounds such as winter re-laying of portable new turf (Orchard et al., 2008), but also under-surface heating and artificial fibre reinforcement of natural grass. Nevertheless, the unsolved dilemma is that both weather and surface conditions interact with footwear at the time of injury, and little is known about the optimum balance between high shoe-surface traction giving a good "grip" in the pitch, but that might produce excessive forces on knees and ankles, and low shoe-surface traction that might result in slipping and a negative influence on performance (Ekstrand \& Nigg, 1989;

Orchard, 2002). As difficult as it would be to characterize grass profile, it would be even more arduous to collect data on players' shoe selections for each exposure, since they test and consume a considerable amount of shoes during a season. However, although little research has been published in the field of football biomechanics related to footwear (Hennig, 2011), no differences in knee joint loading have been found between various round-studded or bladed shoes during sidestep cutting and turning in laboratory field testing in male players (Gehring et al., 2007; Kaila, 2007).

\section{Methodological considerations}

The validation of our study design has been published previously (Hägglund et al., 2005b), and it 
strictly complies with the consensus statement for football injury surveillance (Fuller et al., 2006). In this statement, the strengths and limitations of studies such as this one are thoroughly discussed and will therefore not be repeated here in detail. Briefly, the prospective design, the long observation period to avoid the influence of occasional extreme weather seasons, and the rigorous data check-up with low drop-out figures for individual variables are some important strengths of this study.

Nevertheless, in addition to the limitations already discussed, this study has some further weaknesses that have to be recognised. First, although the study was conducted over several seasons in a homogenous population of professional footballers, the number of teams included in the Southern group was limited and only a few teams were included from each country. It is therefore not clear if the differences reported here represent characteristics of these teams or if they can be generalised to other first league teams in the region. Secondly, since many of the participating clubs are very successful, they do not only compete domestically but also in the UEFA Champions League or the UEFA Europe League (former known as the UEFA Cup). On top of that many players have international duties and they can therefore be exposed to various climate types when playing away matches abroad with the club or during national team matches.

Unfortunately, the design of the exposure record did not include specification of the match city for tournaments, away matches or international duties and it was therefore not possible to adjust for this. Finally, some of the teams (e.g. in Scotland and the Netherlands) have played a few away matches on artificial turf during the study period, and even if the shoe-surface traction might be different on artificial turf than on natural grass (Orchard \& Powell, 2003), the exposure on artificial turf is negligible. It has also been shown for elite teams having third-generation artificial turf on their home facilities that the overall injury incidence does not differ between play on artificial turf 
2013-08-22

compared to natural grass (Ekstrand et al., 2006). 


\section{PERSPECTIVES}

Football is the most popular sport worldwide and is played under various climate conditions. However, knowledge about the influence of regional differences on the injury epidemiology is limited. In this study on selected high-level professional football clubs in Europe, we found that teams from geographical regions with milder summers and cooler winters had a higher injury incidence in general compared to teams with a Mediterranean climate. The injury types which followed this general trend included upper body injuries, low back injuries and Achilles tendinopathy. However, the ACL injury incidence, in particular for non-contact injury, followed the reverse trend and was significantly higher in teams with a Mediterranean climate. The higher ACL injury incidence with warmer climate possibly reflects increased shoe-surface traction, but needs to be studied further. Furthermore, the underlying factors contributing to the higher general injury incidence among teams coming from the north should be studied in the future. In conclusion, regional differences seem to be an important factor to take into account when football teams from different countries are studied or when introducing preventive measures in different geographical regions. 


\section{Acknowledgements}

The authors would like to thank the participating clubs with all their players, coaching staff and medical staff. Dr Markus Kottek is acknowledged for help with categorizing the different groups, and Mr Henrik Magnusson for statistical advice.

The study was supported by grants from the UEFA Football Development Division and the Swedish National Centre for Research in Sports. 


\section{REFERENCES}

Alentorn-Geli E, Myer GD, Silvers HJ, Samitier G, Romero D, Lázaro-Haro C, Cugat R.

Prevention of non-contact anterior cruciate ligament injuries in soccer players. Part 1: Mechanisms of injury and underlying risk factors. Knee Surg Sports Traumatol Arthrosc 2009: 17: 705-729.

Andersen TE, Engebretsen L, Bahr R. Rule violations as a cause of injuries in male Norwegian professional football. Are the referees doing their job? Am J Sports Med 2004: 32: S62-S68.

Bahr R, Holme I. Risk factors for sports injuries - a methodological approach. Br J Sports Med 2003: 37: 384-392.

Bahr R. No injuries, but plenty of pain? On the methodology for recording overuse symptoms in sports. Br J Sports Med 2009: 43: 966-972.

Ekstrand J, Nigg BM. Surface-related injuries in soccer. Sports Med 1989: 8: 56-62.

Ekstrand J, Timpka T, Hägglund M. Risk of injury in elite football played on artificial turf versus natural grass: a prospective two-cohort study. Br J Sports Med 2006: 40: 975-980.

Ekstrand J, Hägglund M, Waldén M. Injury incidence and injury patterns in professional football - the UEFA Injury Study. Br J Sports Med 2011: 45: 553-558.

Fuller CW, Junge A, Dvorak J. An assessment of football referees’ decisions in incidents leading to player injuries. Am J Sports Med 2004: 32: S17-S22. 
Fuller CW, Ekstrand J, Junge A, Andersen TE, Bahr R, Dvorak J, Hägglund M, McCrory P, Meeuwisse WH. Consensus statement on injury definitions and data collection procedures in studies of football (soccer) injuries. Br J Sports Med 2006: 40: 193-201.

Gehring D, Rott F, Stapelfeldt B, Gollhofer A. Effect of soccer shoe cleats on knee joint loads. Int J Sports Med 2007: 28: 1030-1034.

Hennig EM. The influence of soccer shoe design on player performance and injuries. Res Sports Med 2011:19:186-201.

Hägglund M, Waldén M, Ekstrand J. Injury incidence and distribution in elite football - a prospective study of the Danish and the Swedish top divisions. Scand J Med Sci Sports 2005: 15: 21-28.

Hägglund M, Waldén M, Bahr R, Ekstrand J. Methods for epidemiological study of injuries to professional football players - developing the UEFA model. Br J Sports Med 2005: 39: 340-346.

Jacobson I, Tegner Y. Injuries among female football players - with special emphasis on regional differences. Adv Physiother 2006: 8: 66-74.

Kaila R. Influence of modern studded and bladed soccer boots and sidestep cutting on knee loading during match play conditions. Am J Sports Med 2007: 35: 1528-1536.

Kottek M, Grieser J, Beck C, Rudolf B, Rubel F. World map of the Köppen-Geiger climate 
classification updated. Meteorol Z 2006: 15: 259-263.

Lindenfeld TN, Schmitt DJ, Hendy MP, Mangine RE, Noyes FR. Incidence of injury in indoor soccer. Am J Sports Med 1994: 22: 364-371.

Murphy DF, Connolly DA, Beynnon BD. Risk factors for lower extremity injury: a review of the literature. Br J Sports Med 2003: 37: 13-29.

Orchard J, Seward H, McGivern J, Hood S. Rainfall, evaporation and the risk of non-contact anterior cruciate ligament injury in the Australian Football League. Med J Aust 1999: 170: 304306.

Orchard J. Is there a relationship between ground and climatic conditions and injuries in football. Sports Med 2002: 32: 419-432.

Orchard J, Powell JW. Risk of knee and ankle sprains under various weather conditions in American football. Med Sci Sports Exerc 2003: 35: 1118-1123.

Orchard JW, Chivers I, Aldous D, Bennell K, Seward H. Rye grass is associated with fewer noncontact anterior cruciate ligament injuries than Bermuda grass. Br J Sports Med 2005: 39: 704-709.

Orchard J, Rodas G, Til L, Ardevòl J, Chivers I. A hypothesis: could portable natural grass be a risk factor for knee injuries? J Sports Sci Med 2008: 7: 184-190. 
2013-08-22

Waldén M, Hägglund M, Ekstrand J. UEFA Champions League study: a prospective study of injuries in professional football during the 2001-2002 season. Br J Sports Med 2005: 39: 542-546.

Waldén M, Hägglund M, Magnusson H, Ekstrand J. Anterior cruciate ligament injury in elite football: a prospective three-cohort study. Knee Surg Sports Traumatol Arthrosc 2011: 19: 11-19. 
Table 1. Operational definitions used in the study.

\begin{tabular}{ll}
\hline Exposure & Training or match play with the first or reserve team of the club or with a youth or senior national team. \\
Training session & Team training that involved physical activity under the supervision of the coaching staff. \\
Match & Competitive or friendly match against another team. \\
Injury & Physical complaint leading to a player being unable to fully participate in future training or match play. \\
Traumatic injury & Injury with sudden onset and known cause. \\
Overuse injury & Injury with insidious onset and no known trauma. \\
Injury severity & Number of days elapsed from injury to full participation in training and availability for match selection. \\
Minimal & Injury causing lay-off of $1-3$ days from training and match play. \\
Mild & Injury causing lay-off of $4-7$ days from training and match play. \\
Moderate & Injury causing lay-off of $8-28$ days from training and match play. \\
Severe & Injury causing lay-off of $>28$ days from training and match play. \\
Injury incidence & Number of injuries per 1000 player hours [ $\Sigma$ injuries $/ \Sigma$ exposure hours $) \times 1,000]$. \\
\hline
\end{tabular}


Table 2. Clubs included from European professional football and categorization of climate types.

\begin{tabular}{|c|c|c|c|c|c|c|c|c|c|c|}
\hline & Climate* & $01 / 02$ & $02 / 03$ & 03/04 & $04 / 05$ & $05 / 06$ & 06/07 & $07 / 08$ & $08 / 09$ & $09 / 10$ \\
\hline \multicolumn{11}{|l|}{ Northern group } \\
\hline \multicolumn{11}{|c|}{ Scotland (Scottish Premier League) } \\
\hline Rangers FC & $\mathrm{Cfb}$ & & & & & $\mathrm{x}$ & & & & \\
\hline \multicolumn{11}{|c|}{ England (Premier League) } \\
\hline Arsenal FC & $\mathrm{Cfb}$ & $\mathrm{X}$ & $\mathrm{X}$ & $\mathrm{X}$ & $\mathrm{X}$ & $\mathrm{X}$ & $\mathrm{X}$ & $\mathrm{X}$ & $\mathrm{X}$ & $\mathrm{X}$ \\
\hline Chelsea FC & $\mathrm{Cfb}$ & & & & & $\mathrm{X}$ & $\mathrm{X}$ & $\mathrm{X}$ & & \\
\hline Liverpool FC & $\mathrm{Cfb}$ & & & & & $\mathrm{X}$ & $\mathrm{x} \dagger$ & & & $\mathrm{X}$ \\
\hline Manchester United FC & $\mathrm{Cfb}$ & $\mathrm{X}$ & $\mathrm{x}$ & $\mathrm{X}$ & $\mathrm{X}$ & $\mathrm{x}$ & $\mathrm{X}$ & $\mathrm{X}$ & $\mathrm{X}$ & \\
\hline Newcastle United FC & $\mathrm{Cfb}$ & & & & & & $\mathrm{X}$ & & & \\
\hline \multicolumn{11}{|l|}{ France (Ligue 1) } \\
\hline RC Lens & $\mathrm{Cfb}$ & $\mathrm{X}$ & $\mathrm{X}$ & $\mathrm{X}$ & & & & & & \\
\hline Paris St Germain FC & $\mathrm{Cfb}$ & $\mathrm{X}$ & $\mathrm{X}$ & $\mathrm{x} \dagger$ & $\mathrm{X}$ & $\mathrm{X}$ & $\mathrm{X}$ & & & \\
\hline Stade Rennais FC & $\mathrm{Cfb}$ & $\mathrm{X}$ & $\mathrm{X}$ & & & & & & & \\
\hline Olympique Lyonnais & $\mathrm{Cfb}$ & & & & & & & & $\mathrm{X}$ & $\mathrm{X}$ \\
\hline \multicolumn{11}{|c|}{ The Netherlands (Eredivisie) } \\
\hline AFC Ajax & $\mathrm{Cfb}$ & $\mathrm{X}$ & & & & $\mathrm{X}$ & $\mathrm{X}$ & $\mathrm{X}$ & $\mathrm{X}$ & $\mathrm{X}$ \\
\hline PSV Eindhoven & $\mathrm{Cfb}$ & $\mathrm{X}$ & $\mathrm{X}$ & $\mathrm{X}$ & $\mathrm{X}$ & $\mathrm{X}$ & $\mathrm{X}$ & $\mathrm{X}$ & $\mathrm{X}$ & $\mathrm{X}$ \\
\hline \multicolumn{11}{|c|}{ Belgium (Jupiler Pro League) } \\
\hline RSC Anderlecht & $\mathrm{Cfb}$ & & & & & & $\mathrm{X}$ & $\mathrm{X}$ & $\mathrm{X}$ & \\
\hline Club Brugge KV & $\mathrm{Cfb}$ & & & $\mathrm{X}$ & $\mathrm{X}$ & $\mathrm{X}$ & $\mathrm{X}$ & $\mathrm{X}$ & $\mathrm{X}$ & $\mathrm{X}$ \\
\hline \multicolumn{11}{|c|}{ Germany (1. Bundesliga) } \\
\hline BVB Dortmund & $\mathrm{Cfb}$ & & & & & $\mathrm{X}$ & & & & $\mathrm{X}$ \\
\hline Hamburger SV & $\mathrm{Cfb}$ & & & & & & $\mathrm{X}$ & $\mathrm{X}$ & $\mathrm{X}$ & $\mathrm{X}$ \\
\hline FC Bayern München & $\mathrm{Cfb}$ & & & & & & & & & $\mathrm{X}$ \\
\hline \multicolumn{11}{|l|}{ Italy (Serie A) } \\
\hline AC Milan & $\mathrm{Cfa}$ & $\mathrm{X}$ & $\mathrm{X}$ & $\mathrm{x} \dagger$ & & $\mathrm{X}$ & $\mathrm{X}$ & & $\mathrm{x} \dagger$ & $\mathrm{X}$ \\
\hline FC Inter & $\mathrm{Cfa}$ & $\mathrm{X}$ & $\mathrm{X}$ & $\mathrm{X}$ & $\mathrm{X}$ & $\mathrm{X}$ & $\mathrm{X}$ & $\mathrm{X}$ & $\mathrm{X}$ & $\mathrm{X}$ \\
\hline Juventus FC & Cfa & $\mathrm{X}$ & & $\mathrm{X}$ & $\mathrm{X}$ & $\mathrm{X}$ & & & $\mathrm{X}$ & $\mathrm{X}$ \\
\hline \multicolumn{11}{|l|}{ Southern group } \\
\hline \multicolumn{11}{|l|}{ Italy (Serie A) } \\
\hline AFC Fiorentina & Csa & & & & & & & & & $\mathrm{X}$ \\
\hline \multicolumn{11}{|l|}{ Portugal (Liga Sagres) } \\
\hline SL Benfica & Csa & & & & & $\mathrm{X}$ & $\mathrm{X}$ & $\mathrm{X}$ & $\mathrm{X}$ & $\mathrm{X}$ \\
\hline
\end{tabular}


FC Porto

Spain (Primera División)

FC Barcelona

Real Madrid CF
Csb

$\mathrm{X}$

X

X

X

X

* Clubs were categorized into a Northern group (Cfa and Cfb) and a Southern group (Csa and Csb) according to the Köppen-Geiger climate classification system (Kottek et al., 2006).

† Injury and exposure data recorded for approximately half season only. 
Table 3. Regional differences in number and incidence of injuries in European professional football between the 2001/02 and 2009/10 seasons.

\begin{tabular}{|c|c|c|c|c|c|c|}
\hline & \multicolumn{2}{|c|}{ Northern group* } & \multicolumn{2}{|c|}{ Southern group* } & \multirow[t]{2}{*}{ Rate ratio } & \multirow[t]{2}{*}{ Pvalue } \\
\hline & Injuries & Incidence† & Injuries & Incidence† & & \\
\hline \multicolumn{7}{|l|}{ Injuries } \\
\hline Training & 2035 & 4.08 (3.90 to 4.26$)$ & 528 & 3.52 (3.23 to 3.83 ) & 1.16 (1.05 to 1.27$)$ & 0.003 \\
\hline Match & 2664 & 27.68 (26.64 to 28.75$)$ & 722 & 25.68 (23.87 to 27.62 ) & 1.08 (0.99 to 1.17$)$ & 0.07 \\
\hline Total & 4699 & 7.89 (7.67 to 8.12$)$ & 1250 & 7.02 (6.64 to 7.42 ) & 1.12 (1.06 to 1.20$)$ & $<0.001$ \\
\hline \multicolumn{7}{|c|}{ Injury mechanism $\ddagger$} \\
\hline Trauma & 3272 & 5.49 (5.31 to 5.69 ) & 892 & 5.01 (4.69 to 5.35 ) & 1.10 (1.02 to 1.18$)$ & 0.01 \\
\hline Overuse & 1383 & 2.32 (2.20 to 2.45 ) & 348 & 1.95 (1.76 to 2.17 ) & 1.19 (1.06 to 1.34$)$ & 0.004 \\
\hline \multicolumn{7}{|c|}{ Injury severity } \\
\hline Minimal & 920 & 1.54 (1.45 to 1.65$)$ & 299 & 1.68 (1.50 to 1.88$)$ & 0.92 (0.81 to 1.05$)$ & 0.21 \\
\hline Mild & 1201 & 2.02 (1.91 to 2.13 ) & 303 & 1.70 (1.52 to 1.90$)$ & 1.19 (1.04 to 1.34$)$ & 0.008 \\
\hline Moderate & 1787 & 3.00 (2.86 to 3.14 ) & 465 & 2.61 (2.38 to 2.86 ) & 1.15 (1.04 to 1.27$)$ & 0.008 \\
\hline Severe & 791 & 1.33 (1.24 to 1.42$)$ & 183 & 1.03 (0.89 to 1.19$)$ & 1.29 (1.10 to 1.52$)$ & 0.002 \\
\hline
\end{tabular}

* Clubs were categorized into a Northern group (Cfa and Cfb) and a Southern group (Csa and Csb) according to the Köppen-Geiger climate classification system (Kottek et al., 2006).

† Injury incidence is expressed as the number of injuries per 1000 exposure hours with 95\% confidence interval (95\% CI).

‡ Data were missing for 54 injuries. 
Table 4. Regional differences in number and incidence of injuries according to location and type in European professional football between the 2001/02 and 2009/10 seasons.

\begin{tabular}{|c|c|c|c|c|c|c|}
\hline & \multicolumn{2}{|c|}{ Northern group* } & \multicolumn{2}{|c|}{ Southern group* } & \multirow[t]{2}{*}{ Rate ratio } & \multirow[t]{2}{*}{ Pvalue } \\
\hline & Injuries & Incidence† & Injuries & Incidence† & & \\
\hline Head/ neck & 111 & 0.19 (0.15 to & 19 & 0.11 (0.07 to & 1.75 (1.07 to & 0.03 \\
\hline \multirow[t]{3}{*}{ Concussion } & 41 & $0.22)$ & 5 & $0.17)$ & 2.84) & 0.06 \\
\hline & & 0.07 (0.05 to & & 0.03 (0.01 to & 2.45 (0.97 to & \\
\hline & & $0.09)$ & & $0.07)$ & $6.20)$ & \\
\hline \multirow[t]{2}{*}{ Upper extremity } & 164 & $0.28(0.24$ to & 32 & 0.18 (0.13 to & 1.53 (1.05 to & 0.03 \\
\hline & & 1.32) & & $0.25)$ & $2.24)$ & \\
\hline Trunk & 343 & 0.58 (0.52 to & 52 & $0.29(0.22$ to & 1.97 (1.47 to & $<0.00$ \\
\hline \multirow[t]{3}{*}{ Low back pain } & 119 & $0.64)$ & 17 & $0.38)$ & 2.64) & 1 \\
\hline & & 0.20 (0.17 to & & 0.10 (0.06 to & 2.09 (1.26 to & 0.004 \\
\hline & & $0.24)$ & & $0.15)$ & $3.48)$ & \\
\hline Hip/groin & 663 & 1.11 (1.03 to & 180 & 1.01 (0.87 to & 1.10 (0.93 to & 0.25 \\
\hline Adductor-related & 429 & $1.20)$ & 128 & 1.17) & 1.30) & 0.98 \\
\hline injuries & 58 & 0.72 (0.66 to & 15 & 0.72 (0.60 to & 1.00 (0.82 to & 0.626 \\
\hline \multirow[t]{3}{*}{ Pubalgia/ hernia } & & $0.79)$ & & $0.85)$ & $1.22)$ & \\
\hline & & 0.10 (0.08 to & & 0.08 (0.05 to & 1.16 (0.66 to & \\
\hline & & $0.13)$ & & $0.14)$ & 2.04) & \\
\hline Thigh & 1142 & 1.92 (1.81 to & 337 & 1.89 (1.70 to & 1.01 (0.90 to & 0.83 \\
\hline Strain/muscle & 906 & 2.03) & 262 & 2.11) & 1.44) & 0.63 \\
\hline rupture & 245 & 1.52 (1.43 to & 64 & 1.47 (1.30 to & 1.03 (0.90 to & 0.34 \\
\hline Quadriceps & 555 & 1.62) & 171 & 1.66) & 1.19) & 0.73 \\
\hline \multirow[t]{4}{*}{ Hamstrings } & & 0.41 (0.36 to & & $0.36(0.28$ to & 1.15 (0.87 to & \\
\hline & & $0.47)$ & & $0.46)$ & 1.51) & \\
\hline & & 0.93 (0.86 to & & $0.96(0.83$ to & 0.97 (0.82 to & \\
\hline & & 1.01) & & 1.12) & 1.15) & \\
\hline Knee & 807 & 1.36 (1.26 to & 236 & 1.33 (1.17 to & 1.02 (0.88 to & 0.76 \\
\hline Sprain/ligament & 331 & $1.45)$ & 85 & 1.51) & $1.18)$ & 0.21 \\
\hline
\end{tabular}




\begin{tabular}{|c|c|c|c|c|c|c|}
\hline rupture & 211 & 0.56 (0.50 to & 54 & $0.48(0.39$ to & $1.16(0.92$ to & 0.31 \\
\hline MCL $\ddagger$ & 29 & $0.62)$ & 20 & $0.59)$ & $1.48)$ & 0.004 \\
\hline $\mathrm{ACL} \ddagger$ & 116 & 0.35 (0.31 to & 24 & $0.30(0.23$ to & 1.17 (0.87 to & 0.10 \\
\hline Meniscus/ cartilage & 57 & $0.41)$ & 23 & $0.40)$ & $1.56)$ & 0.23 \\
\hline Patellar & & 0.05 (0.03 to & & 0.11 (0.07 to & $0.43(0.25$ to & \\
\hline \multirow[t]{5}{*}{ tendinopathy } & & $0.07)$ & & $0.17)$ & $0.77)$ & \\
\hline & & 0.19 (0.16 to & & 0.13 (0.09 to & 1.46 (0.93 to & \\
\hline & & $0.23)$ & & $0.19)$ & $2.24)$ & \\
\hline & & $0.10(0.07$ to & & 0.13 (0.09 to & 0.74 (0.46 to & \\
\hline & & $0.12)$ & & $0.19)$ & 1.20) & \\
\hline Lower leg & 548 & 0.92 (0.85 to & 135 & $0.76(0.64$ to & 1.21 (1.01 to & 0.04 \\
\hline Strain/muscle & 199 & $1.00)$ & 52 & $0.90)$ & 1.47) & 0.39 \\
\hline rupture & 114 & 0.33 (0.29 to & 20 & 0.29 (0.22 to & 1.14 (0.84 to & 0.03 \\
\hline Achilles & & $0.38)$ & & $0.38)$ & 1.55) & \\
\hline \multirow[t]{2}{*}{ tendinopathy } & & 0.19 (0.16 to & & $0.11(0.07$ to & 1.78 (1.06 to & \\
\hline & & $0.23)$ & & $0.17)$ & 2.74) & \\
\hline Ankle & 655 & 1.10 (1.02 to & 181 & 1.02 (0.88 to & $1.08(0.92$ to & 0.44 \\
\hline Sprain/ligament & 413 & 1.19) & 146 & 1.18) & 1.28) & 0.08 \\
\hline rupture & 314 & 0.69 (0.63 to & 73 & $0.82(0.70$ to & 0.85 (0.70 to & 0.05 \\
\hline \multirow[t]{3}{*}{ Lateral ligaments } & & $0.76)$ & & $0.96)$ & 1.02) & \\
\hline & & 0.44 (0.39 to & & 0.41 (0.33 to & 1.08 (0.83 to & \\
\hline & & $0.50)$ & & $0.52)$ & $1.40)$ & \\
\hline \multirow[t]{2}{*}{ Foot } & 263 & 0.44 (0.39 to & 73 & 0.41 (0.33 to & 1.08 (0.83 to & 0.57 \\
\hline & & $0.50)$ & & $0.52)$ & $1.40)$ & \\
\hline
\end{tabular}

* Clubs were categorized into a Northern group (Cfa and Cfb) and a Southern group (Csa and Csb) according to the Köppen-Geiger climate classification system (Kottek et al., 2006).

$†$ Injury incidence is expressed as the number of injuries per 1000 exposure hours with 95\% confidence interval (95\% $\mathrm{CI})$.

$\ddagger$ MCL denotes medial collateral ligament and ACL denotes anterior cruciate ligament. 
2013-08-22

\section{FIGURE LEGENDS}

Figure 1. Regional differences in the seasonal distribution of injury incidence in European professional football between the 2001/02 and 2009/10 seasons.

Figure 2. Regional differences in the seasonal distribution of non-contact ACL injury incidence in European professional football between the 2001/02 and 2009/10 seasons. 


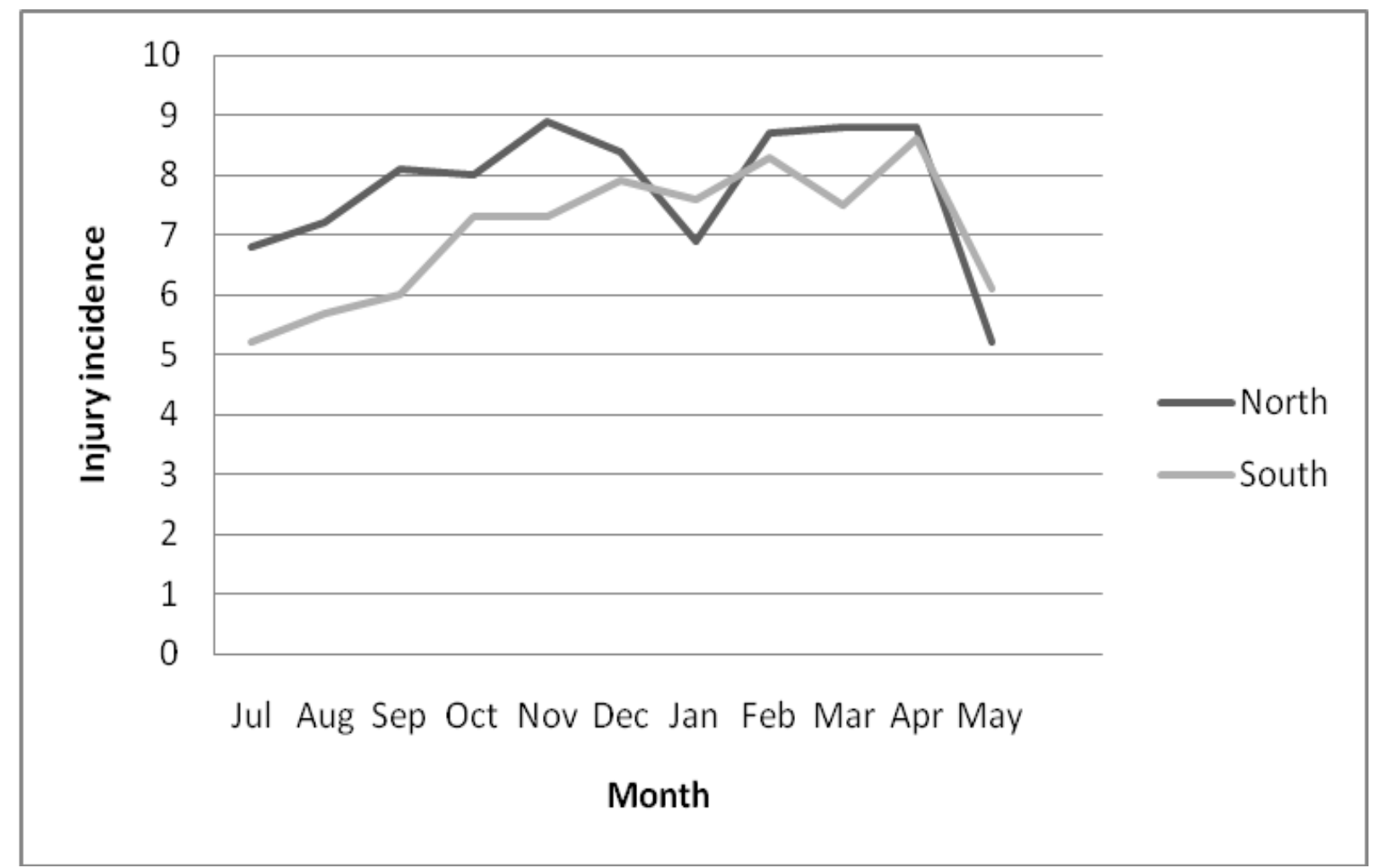

Figure 1. Regional differences in the seasonal distribution of injury incidence in European professional football between the 2001/02 and 2009/10 seasons.

Clubs were categorized into a Northern group (Cfa and Cfb) and a Southern group (Csa and Csb) according to the Köppen-Geiger climate classification system (Kottek et al., 2006).

Injury incidence is expressed as the number of injuries per 1000 hours. 


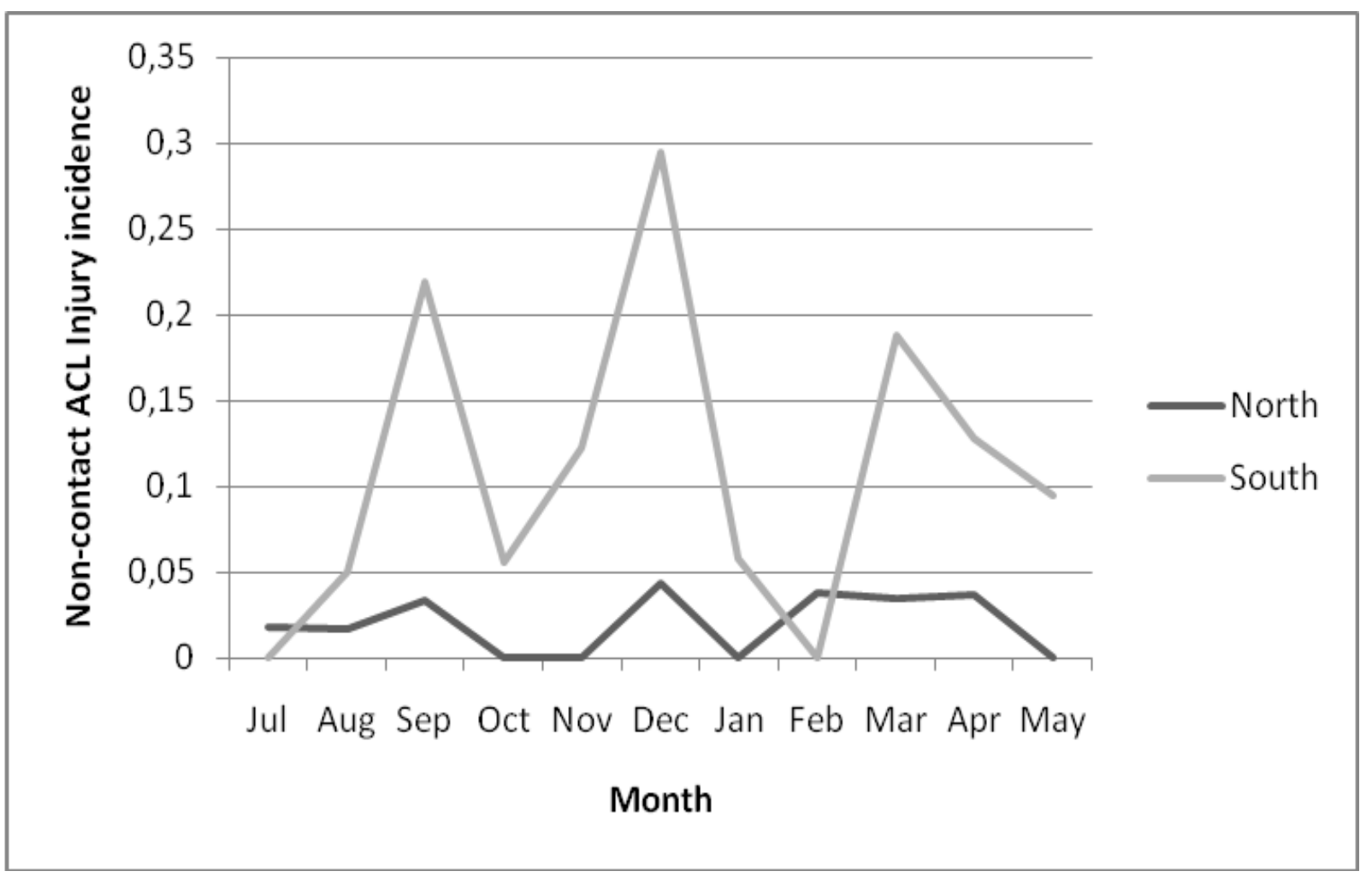

Figure 2. Regional differences in the seasonal distribution of non-contact ACL injury incidence in European professional football between the 2001/02 and 2009/10 seasons.

Clubs were categorized into a Northern group (Cfa and Cfb) and a Southern group (Csa and Csb) according to the Köppen-Geiger climate classification system (Kottek et al., 2006).

Injury incidence is expressed as the number of non-contact ACL injuries per 1000 hours.

ACL denotes anterior cruciate ligament. 